\title{
O SINGULAR NU DENOTA ESPÉCIE: \\ UMA INVESTIGAÇÃO EMPÍRICA
}

\section{(Bare singulars are kind denoting expressions: an empirical investigation)}

\author{
Roberta Pires de Oliveira (UFSC)* \\ Josa Coelho da Silva (UFSC) \\ Mariana Rublescki Silveira Bressane (IC)
}

\begin{abstract}
The paper presents the results of an investigation into oral and written language corpora and of a psycholinguistic experiment on the grammaticality of generic sentences in Brazilian Portuguese with bare singular. There is no consensus in the literature concerning the grammaticality of these sentences (Munn E Schmitt (1999, 2005) vs. Müller (2000, 2002, 2003)). Consequently, there is disagreement about the denotation of bare singulars: for some authors they denote species (Munn E Schmitt), for others, they are indefinites (Müller). Our investigation shows that there are occurrences of bare singular in kind denoting sentences in the corpora, and that at least for some dialects they are grammatical; giving support to Munn \& Schmitt' approach.
\end{abstract}

Key-words: bare singular; kind; semantics; empirical evidence; psycholinguistic experiment.

Resumo: Apresentam-se neste estudo os resultados de investigaşão em banco de dados de lingua falada e escrita e de um experimento psicolinguístico sobre a gramaticalidade de sentenças genéricas com singular nu no português brasileiro. Não bá, na literatura, consenso sobre a gramaticalidade dessas sentenças (Munn E Schmitt $(1999,2005)$ vs. Müller (2000, 2002, 2003). Consequentemente, há autores que entendem que o singular nu denota espécie (Munn E Schmitt); outros que o veem como um indefinido (Müller). Nossa investigação comprova, com dados de língua escrita e falada, a gramaticalidade dessas sentenças; resultado referendado pelo teste psicolinguístico. Assim, certos dialetos conformam-se à abordagem de Munn E Schmitt.

Palavras-chave: singular nu; espécie; semântica; evidência empírica; experimento psicolinguístico.

\footnotetext{
* Agradecemos ao prof. Edson Françoso (Unicamp) e ao doutorando Renato Miguel Basso (Unicamp) pelo apoio na elaboração dos testes e na avaliação dos resultados. A Pablo Arantes agradecemos a verificação estatística dos dados encontrados no teste. Os erros são inteiramente de nossa responsabilidade.
} 


\section{INTRODUÇÃO}

Este artigo apresenta os resultados de uma investigação em banco de dados de língua falada e escrita e de um experimento psicolinguístico original, formulado para verificar a aceitabilidade/gramaticalidade do singular nu no português brasileiro em sentenças com predicados de espécie e sentenças episódicas com leitura genérica. Trata-se de um experimento crucial $^{1}$, porque há, no momento, não apenas julgamentos divergentes quanto à aceitabilidade dessas sentenças - por um lado, Munn \& Schmitt (1999, 2005), Schmitt \& Munn (2002), Santolin (2006), Pires de Oliveira et al. (2006), consideram essas sentenças aceitáveis, por outro, Müller (2000, 2002,2003 ) as toma como agramaticais -, mas principalmente porque a possibilidade do singular nu ocorrer nesses contextos é a garantia de que ele pode denotar espécie, o que tem consequências teóricas para a análise do singular nu em todos os contextos sintáticos em que ele ocorre. Nesse sentido, os resultados desse experimento podem definir uma controvérsia teórica importante para melhor entendermos a interface entre a sintaxe e a semântica dos nominais. Na primeira seção, apresentamos uma rápida descrição do problema teórico envolvido na controvérsia sobre a aceitabilidade do singular nu com predicados de espécie e em sentenças genéricas episódicas. Em seguida, apresentamos os resultados de nossa pesquisa em banco de dados de língua escrita e falada. A terceira seção é dedicada à descrição detalhada do experimento, que tem como base o trabalho de Basso (2007). Finalmente, empreendemos a análise dos resultados desse experimento na quarta seção. Concluímos que há evidências empíricas que sustentam a afirmação de que o singular nu se combina com predicados de espécie e pode ocorrer em sentenças episódicas genéricas. Logo, o singular nu, ao menos em alguns dialetos, pode denotar espécie (como sustentam Munn \& Schmitt (1999, 2005) e Pires de Oliveira et al. (2006), entre outros).

\section{A CONTRovérsia}

Embora não muito extensa (Munn \& Schmitt (1999, 2005), Schmitt \& Munn (2002), Müller (2000, 2002, 2003), Dobrovie-Sorin \& Pires de

1. Evidentemente, o tema do experimento crucial é bastante controverso, como mostram os debates em epistemologia da ciência. Para não entrar nesse debate, adotamos uma noção quase de senso comum, sem assumir que o experimento que estamos propondo possa refutar definitivamente uma teoria. 
Oliveira (2007a, 2007b)), a literatura sobre a denotação do singular nu (dorante $\mathrm{SNu}$ ) no português brasileiro (PB) é controversa. O singular nu é caracterizado por ser um sintagma nominal - em sentido amplo, isto é um sintagma cujo núcleo é um nome - sem um determinante aparente, sendo constituído, portanto, apenas pelo nome ${ }^{2}$, como 'dinossauro' no exemplo em (1) abaixo.

A disputa teórica diz respeito a duas posições antagônicas quanto à possibilidade desse sintagma denotar espécie e aparece explicitada na nota n. 57 de Dayal (2004: 43), que se abstém de analisar o SNu no PB por conta desse desacordo:

There is disagreement about the ability of bare singular in Brazilian Portuguese to denote kinds. Munn and Schmitt (1999) argue that they can while Müller (2002) claims that they cannot.

A controvérsia versa, em primeira instância, sobre a aceitabilidade ou gramaticalidade de sentenças como (1):

(1) Dinossauro está extinto.

Munn \& Schmitt (1999, 2005), Pires de Oliveira et al. (2006), entre outros, entendem que a sentença em (1) é aceitável/gramatical no PB. Se for esse o caso, então o SNu 'dinossauro' denota uma espécie, já que o predicado 'está extinto' seleciona como argumento um indivíduo espécie. Müller (2000, 2002, 2003), por outro lado, julga que a sentença em (1) é agramatical, logo o singular nu 'dinossauro' não pode se referir à espécie ${ }^{3}$.

Esse desacordo sobre o julgamento de aceitabilidade/gramaticalidade de sentenças como em (1) tem como reflexo a exclusão ou inclusão de outras sentenças que, teoricamente, se equiparam a essa sentença, porque compostas por predicados que exigem que o sintagma nominal denote espécie. Assim, sentenças com predicados episódicos, como em (2), têm

2. Neste artigo, não iremos discutir se um sintagma sem determinante acompanhado por adjetivo, como em 'mulher gorda', é ainda um singular nu.

3. Müller, ao apresentar seus julgamentos das sentenças em questão, se ancora na noção de gramaticalidade. Uma noção que, embora crucial, tem recebido pouca atenção. Utilizamos, neste artigo, os termos aceitável e não aceitável, porque estamos lidando diretamente com o julgamento de falantes. No entanto, sentenças agramaticais não deveriam ser produzidas, por isso a análise empírica em banco de dados. Retornaremos a esse tópico ao longo deste artigo. 
a interpretação genérica garantida pelo sintagma nominal que, portanto, denota necessariamente uma espécie. Não há dúvidas de que o definido singular (DS), como 'o café' em (2), denota espécie:

(2) O café foi introduzido no Brasil pelos europeus.

É porque ele denota espécie que a sentença em (2) é genérica. Logo, não há um operador genérico encoberto garantindo sua genericidade ${ }^{4}$. Por isso, é de se esperar que se o $\mathrm{SNu}$ não denota espécie, ele não possa ocorrer em sentenças episódicas como (2). Em consonância com o julgamento de agramaticalidade para a sentença em (1), Müller também rejeita a possibilidade do $\mathrm{SNu}$ se combinar com predicado episódico, gerando uma interpretação genérica. Podemos ver essa rejeição no julgamento que a autora apresenta para a sentença (95) de seu texto, apresentada abaixo com nossa numeração:

(3) * Um automóvel/*Automóvel chegou ao Brasil no século XX. (Muller, 2002: 170)

Em movimento simétrico, Munn \& Schmitt (1999, 2005) e Pires de Oliveira et al. (2006), entre outros, julgam aceitável a sentença em (3) com o singular nu. Novamente, se for esse o caso, então, 'automóvel' denota espécie.

A aceitabilidade/gramaticalidade de sentenças como em (1) e (3) tem importantes consequências não apenas para a atribuição de uma semântica para esse tipo de sentenças, mas tem reflexos na explicação do comportamento do $\mathrm{SNu}$ em outros contextos sintáticos, como veremos adiante. Essa diferença na interpretação semântica pode ser ilustrada através do exemplo em (4), considerado plenamente aceitável por ambas as posições teóricas:

(4) Brasileiro gosta de futebol.

Se o singular nu não denotar espécie, como defende Müller (2000, 2002, 2003), então ele será um indefinido, no sentido de Heim (1982), isto é, ele introduz uma variável e a estrutura semântica dessa sentença será

4. A literatura sobre genéricos entende que sentenças como 'Brasileiro chora' comportam um operador genérico encoberto. Ver mais adiante. 
idêntica a uma sentença com o indefinido genérico como exemplificado em (5). Note o paralelo que Müller estabelece entre o singular nu e o indefinido singular no julgamento das sentenças em (3) acima, ambas consideradas agramaticais naquele contexto:

(5) Um brasileiro gosta de futebol.

Tanto (4) quanto (5) têm, para Müller, a mesma forma lógica:

(6) Gen [x; [ $\mathrm{x}$ é brasileiro] [x gosta de futebol]

Em linguagem menos formal: geralmente se algo é brasileiro, então ele gosta de futebol.

É bom esclarecer que as sentenças em (4) e (5), embora genéricas, não podem nos ajudar a decidir se o $\mathrm{SNu}$ pode ou não denotar espécie, porque a genericidade dessas sentenças não é garantida nem pelo predicado, como é o caso do predicado de espécie, nem pelo sintagma nominal como nas sentenças genéricas episódicas, mas pela presença de um operador genérico invisível, Gen. A questão que interessa é perceber que se Müller está correta, então essas sentenças terão exatamente a mesma forma lógica. Caso contrário, é possível argumentar que elas não têm a mesma forma lógica, como de fato fazem Dobrovie-Sorin e Pires de Oliveira (2007a, 2007b).

Essas autoras mostram que há vários indícios de que o $\mathrm{SNu}$ não se comporta como o indefinido singular ${ }^{5}$. Por exemplo, apenas a sentença em (7a) é ambígua entre uma leitura de re, isto é, de escopo amplo, e uma leitura de dicto, em que o indefinido genérico tem escopo estreito. Na leitura de re, há uma secretária que João está procurando. Essa leitura não existe para (7b), que só pode ser interpretada com escopo estreito, isto é, João está procurando uma secretária qualquer:

(7) a. João procura uma secretária.

b. João procura secretária.

Embora o comportamento distinto do $\mathrm{SNu}$ e do indefinido genérico seja um argumento contra a proposta de Müller (2000, 2002, 2003), esse

5. Ver Sorin \& Pires de Oliveira (2007b) para uma apresentação de vários argumentos contra a hipótese de que o $\mathrm{SNu}$ se comporta como indefinito singular. 
fato não é uma indicação segura de que o singular nu denota espécie. Ele pode simplesmente mostrar que o $\mathrm{SNu}$ e o indefinido genérico não têm o mesmo comportamento.

Outro argumento que problematiza entendermos que o $\mathrm{SNu}$ é um indefinido é a sua ocorrência com predicados de indivíduo (individual level predicates), como em (8), em que ele tem uma leitura genérica:

(8) João ama cachorro.

O SNu está na posição de objeto e, se ele fosse um indefinido, deveria exibir leitura existencial, como ocorre em (9) com o sintagma indefinido, porque quando em posição de objetos esses sintagmas se encontram sob o escopo de um operador existencial:

(9) João ama um cachorro.

No entanto, (8) tem leitura genérica. ${ }^{6}$ É claro que se o $\mathrm{SNu}$ denotar espécie, então ele não se comporta como o indefinido genérico e explicamos os contrastes em (7) e (8).

Como já apontamos, para autores que consideram que o $\mathrm{SNu}$ denota espécie, a sentença em (4) não tem a mesma forma lógica da sentença em (5), que continua a ser representada como em (6). Sem entrar nos detalhes, mas apenas para mostrarmos as diferenças de análise, apresentamos brevemente a proposta de Dobrovie-Sorin \& Pires de Oliveira (2007a) para a semântica do $\mathrm{SNu}$, segundo a qual a sentença em (4) recebe a seguinte forma lógica (as autoras baseiam-se na proposta de Chierchia (1995) para o plural nu no inglês):

(10) Gen $x$ [ $\cup \cap \mathrm{x}$ é brasileiro] [x gosta de futebol]

Em prosa: em geral, os indivíduos derivados da soma máxima de brasileiro gostam de futebol.

Nessa sentença, un indicam a aplicação de duas operações semânticas. O operador down, representado por ${ }^{\cap}$, aplica-se a uma propriedade,

6. Kratzer (1995) propõe para o plural nu no inglês que os predicados de indivíduo forçam uma operação de "scrambling" do objeto. Não iremos discutir essa questão. 
'brasileiro', e engendra a soma intensional máxima de indivíduos (de acordo com o modelo de Link (1983)). Em seguida, aplica-se o operador up $\backsim$ que retorna os indivíduos que compõem essa soma. A generalização é feita para esses indíviduos. Veja que a sentença em (10) não é efetivamente sobre a "espécie" brasileiro, mas sobre os indivíduos, por isso a necessidade da operação $u p$ : em geral os indivíduos que têm a propriedade de ser brasileiro gostam de futebol. O leitor pode estar se perguntando porque é necessário uma operação de formação de soma, a operação down. Para entender esse passo, considere novamente a sentença em (1), cuja forma lógica aparece em (11):

(11) $\cap$ Dinossauro Está-extinto.

Informalmente, afirma-se que o predicado 'está-extinto' aplica-se à soma máxima de indivíduos. Como mostram Dobrovie-Sorin e Pires de Oliveira (2007a, b), não é possível atribuir a mesma semântica para o definido genérico, como em (12), e o SNu em (1):

(12) O dinossauro está extinto.

Embora ambos denotem espécie, eles o fazem através de mecanismos distintos. O definido singular denota um indivíduo espécie diretamente, ao passo que em (1), de acordo com a forma lógica em (11), a referência à espécie é realizada indiretamente, através do recurso à soma máxima. Para Müller, não há forma lógica para a sentença em (1), porque ela não é gramatical. Sobre o definido singular em (10), a autora afirma que ele denota a espécie dinossauro, mas não se pronuncia quanto a sua semântica ${ }^{7}$.

O ponto crucial para termos duas semânticas para a denotação da espécie reside no tato de que somente assim é possível explicarmos os vários contrastes entre o uso do singular nu e do definido genérico. A literatura (Krifka et al. 1995) já notou que o definido genérico só denota espécies bem estabelecidas, apenas a sentença em (13a) tem leitura genérica:

7. Chierchia (1995, 1998) e Dayal (2002), por exemplo, apresentam duas propostas totalmente distintas para a semântica do singular definido genérico, embora ambos afirmem que ele denota espécie. 
(13) a. A garrafa de Coca tem gargalo estreito.

b. A garrafa azul tem gargalo estreito.

(13b) é sobre um indivíduo que não é uma espécie. Essa restrição não se aplica aos nominais nus. Tanto (14a) quanto (14b) são sentenças genéricas:

(14) a. Garrafa de Coca tem gargalo estreito.

b. Garrafa azul tem gargalo estreito.

Dobrovie-Sorin e Pires de Oliveira (2007a, b) explicam esse e outros contrastes propondo que o sintagma nominal em que o $\mathrm{SNu}$ ocorre é encabeçado por um determinante nulo (seguindo a proposta de Schmitt \& Munn (2002, entre outros)) que funciona como um operador down, modificando o tipo semântico de predicado para indivíduo, sendo esse indivíduo a soma máxima intensional. Essa é a proposta de Chierchia (1998) para o plural nu em inglês que também denota espécie indiretamente.

Como é possível notar, inclusive pela citação de Dayal, decidirmos sobre a aceitabilidade ou não de sentenças como (1) é um experimento crucial para a pesquisa na área da interface sintaxe/semântica dos nominais, no sentido de que tal decisão indica qual é a teoria mais apropriada. Para tanto precisamos de métodos empíricos confiáveis. Nossa primeira tentativa para verificar se o $\mathrm{SNu}$ denota espécie foi vasculhar banco de dados a procura de ocorrências do $\mathrm{SNu}$ com predicados de espécie. Os resultados dessa busca são apresentados na próxima seção.

\section{O RESUlTADO DA BUSCA EM CORPORA}

O primeiro passo desta pesquisa foi vasculhar bancos de dados, procurando ocorrências de sintagmas nus com predicados de espécie, na posição de sujeito. Os predicados de espécie, isto é, aqueles que selecionam um argumento que denota espécie, são poucos e não há consenso na literatura sobre todos eles - por exemplo, Chierchia $(1995,1998)$ considera que 'widespread' (espalhado) é um predicado de espécie, tese contestada por Krifka et al. (1995). Nossa busca centrou-se nos predicados que são indiscutivelmente de espécie: 'extinguir', 'acabar', como sinônimo de 'extinguir', 
e 'desaparecer'; em todas suas variantes de tempo e aspecto ('está extinto', 'está se extinguindo', por exemplo). Recorreu-se a dois bancos de dados de língua falada: Nurc e Varsul ${ }^{8}$. O que se constatou imediatamente é que há pouquíssimas ocorrências desses predicados nesses bancos de dados.

Em relação ao Nurc, foram analisadas 154 amostras de entrevistas orais, sendo que houve apenas duas ocorrências do predicado 'extinto' uma acompanhada de sintagma definido, exemplo em (15), e outra com sintagma indefinido, exemplo em (16):

(15) O armazém é uma espécie, quer dizer, acho que já é extinto, né? (Inq0233)

(16) Um meio de comunicação que já já já tá se extinguindo. (REC-05-D2)

Vale notar que (16) se conforma com o que a literatura afirma sobre o indefinido genérico (Krifka et al. 1995; Müller 2002): quando combinado com um predicado de espécie ele gera uma leitura taxonômica, isto é, trata-se de uma subespécie.

O Varsul, com aproximadamente 288 entrevistas registradas, também não apresentou um número relevante de predicados de espécie para a pesquisa. Nesse corpus, apenas 20 sentenças foram selecionadas. Esse resultado mostra o que já apontamos: predicados de espécie são pouquíssimo utilizados na fala espontânea do PB, se levarmos em consideração esses corpora.

Há um grande número de ocorrências do verbo 'acabar', mas poucas delas como sinônimo de 'extinguir' (18 no total); dessas houve uma única ocorrência com o sintagma singular nu, exemplo em (17), as demais foram todas com plural nu. Mesmo assim, esse é sem dúvida um dado importante, já que encontramos uma ocorrência de $\mathrm{SNu}$ com um predicado de espécie em fala espontânea. Essa ocorrência já é suficiente para descartamos que tal combinação é agramatical, se entendermos que supostamente os falantes não produzem espontaneamente sentenças agramaticais. Nesse sentido, esse dado questiona uma leitura forte da teoria apresentada por Müller, já que ela prevê que esse dado não deveria ocorrer. Assim, encontrá-lo é um argumento a favor da hipótese de que o $\mathrm{SNu}$ pode denotar espécie:

(17) Agricultura vai acabar em dois anos. (0001: SL 0353)

8. Agradecemos aos responsáveis pelos bancos de dados por terem permitido que realizássemos essa pesquisa. 
É preciso, no entanto, certa cautela porque além de esse ter sido o único dado encontrado, tem como núcleo do sintagma nominal 'agricultura', um termo que parece ser abstrato. A questão é que a literatura, até onde pudemos investigar, não explicita exatamente o que se entende por "espécie". O termo utilizado é "kind" que tem uma abrangência maior do que "espécie" no português; já que "espécie" parece ser restrito a seres vivos, enquanto "kind" pode ser usado sem essa restrição. Tanto é assim que um dos casos mais discutidos na literatura diz respeito ao contraste entre espécie ("kind") bem estabelecida, como a espécie garrafa de Coca-Cola, e espécie não bem estabelecida, como garrafa azul, que apareceram nos exemplos em (13) e (14). De qualquer forma, é possível argumentar que 'agricultura' denota uma espécie de atividade.

As outras ocorrências eram acompanhadas de sintagmas definidos plurais como no exemplo em (18):

(18) E depois os grandes fazendeiros se acabaram. (0001: SL 0805)

Quanto ao verbo 'desaparecer', houve apenas uma única ocorrência como predicado de espécie, também acompanhada de sintagma definido:

(19) vinte ou trinta anos atrás parecia que ia desaparecer o cavalo, né? (0001: SL 0435)

Já o verbo 'extinguir' apareceu uma única vez, mas não como um predicado de espécie, referindo-se a um evento em particular:

(20) É um trabalho muito bonito que está quase em extinção. (0001: SL 0442)

A análise dos bancos de dados apenas apontou que o SNu é compatível com predicado de espécie, mas como uma indicação fraca, já que encontramos um único dado confirmando essa hipótese (exemplo (17)). Esse resultado, embora promissor, nos pareceu ser insuficiente para decidirmos uma questão teórica tão complexa.

Uma investigação em dados de língua escrita (nos sites de Folha de $S$. Paulo, $O$ Globo e por meio do buscador Google) mostrou que há um enorme uso de $\mathrm{SNu}$ com predicados de espécie. A grande maioria aparece nos chamados lead de textos jornalísticos, como exemplificado abaixo: 
(21) Boto chinês está extinto, dizem cientistas. (Disponível em: http://g1.globo. com/Noticias/Ciencia/0,,MUL84659-5603,00.html; acesso em: 11 abr. 2010)

(22) Pesquisa comprova que jacaré não está em extinção no Pantanal. (Disponível em: http://www.mail-archive.com/dtoambiental@listserv.pegasus.com.br/ msg00280.html; acesso em: 11 abr. 2010)

Poder-se-ia argumentar que a ocorrência em chamadas de textos jornalísticos não é relevante para a disputa em questão, porque esse gênero de texto tem características bem peculiares. Por exemplo, o presente simples, em geral utilizado para expressar genericidade, aparece nesse tipo de contexto com interpretação de pretérito perfeito. É também comum encontrarmos o $\mathrm{SNu}$ com interpretação (quase) definida em leads, como em: "Ladrão invade o Senado". No entanto, é importante ressaltar que, nos exemplos acima, os SNus não têm leitura específica, ao contrário, referem-se efetivamente à espécie. É por isso que podemos utilizá-los como argumento para a hipótese de que o $\mathrm{SNu}$ denota espécie.

Além disso, as ocorrências do $\mathrm{SNu}$ no corpo do texto ou de uma fala são também bastante frequentes. Abaixo alguns exemplos:

(23) Infelizmente, mas bota infelizmente nisso, nosso povo é ignorante e acomodado. A grande maioria não se esforça nem um pouco para se informar e pensar sobre coisas que vão além do lugar comum. Isso explica, na minha modesta opinião, o espanto dos infelizes que acham que LP está extinto.

(Disponível em: http://www.htforum.com/vb/showthread. php? $\mathrm{t}=56565$ \&page $=2$; acesso em: 11 abr. 2010)

(24) Autoritarismo está extinto pelo mundo afora.

(Disponível em: http://blog.estadao.com.br/blog/padiglione/?title=a_sao_ paulo_das_novelas_da_globo_volta_a\&more $=1 \& \mathrm{c}=1 \& \mathrm{tb}=1 \& \mathrm{pb}=1$; acesso em: $1 \overline{1}$ abr. 2010)

(25) Nota fiscal, lucro, comércio, tudo isso está extinto.

(Disponível em: http://www.sonhospostumos.weblogger.terra.com.br/200704 sonhospostumos; acesso em: 11 abr. 2010)

Os exemplos acima foram retirados de blogs e, particularmente o exemplo em (23) tem claramente marcas de oralidade. Poder-se-ia, mais uma vez, argumentar que nessas sentenças o núcleo do sintagma não é claramente de espécie. No entanto, com exceção de ‘autoritarismo’ em 
(24), que se assemelha à 'agricultura', os demais exemplos se enquadram na definição de espécie tal qual presente na literatura, ainda que não haja, como já apontamos e até onde pudemos verificar, uma discussão explícita sobre o que exatamente está se entendendo por esse termo. Em (23) temos um caso incontestável de SNu com predicado de espécie, 'LP', constituindo mais um contra-argumento à tese de Müller (2000, 2002, 2003). Assim, embora impressionística, a análise dos dados da internet, aponta ocorrências efetivas em que $\mathrm{SNu}$ é utilizado como argumento de predicados de espécie, um resultado inesperado tendo em vista a proposta de Müller (2000, entre outros) para quem essa combinação é agramatical. Se fosse agramatical não deveríamos esperar nenhuma ocorrência.

\section{O TESTE PSiCOlinguístico DE ACEITABILIDAdE}

Embora os resultados da pesquisa nos bancos de dados de língua falada e escrita sejam relevantes para os objetivos deste artigo, não o foram de maneira totalmente convincente, porque, nos dados de oralidade achamos um único exemplo, e os demais são dados de escrita, ainda que no caso de blogs eles sejam fortemente orais. Decidimos, então, partir para aplicação de um teste psicolinguístico de aceitabilidade visando verificar se sentenças com o singular nu denotando espécie são ou não aceitáveis e qual o grau de aceitabilidade que elas apresentam. Utilizamos o conceito de aceitabilidade porque estamos avaliando se os falantes consideram que a sentença é "normal" ou se há algum tipo de anomalia. Para a elaboração do teste baseamo-nos em Basso (2007, em particular no capítulo 4).

De acordo com a metodologia ali exposta, elaboramos 36 sentenças, das quais 24 são experimentais e 12 são distratoras, isto é, sentenças que aparecem com a função de não permitir que os sujeitos da pesquisa percebam o que está sendo testado. Abaixo a lista das sentenças distratoras. Vale notar que algumas são inaceitáveis. Incluímos sentenças inaceitáveis para podermos comparar os resultados obtidos com as sentenças com singular nu. O raciocínio é o seguinte: se as sentenças com $\mathrm{SNu}$ forem inaceitáveis, elas devem apresentar índices parecidos com as outras sentenças que são claramente inaceitáveis, como é o caso das sentenças (26f) e (26j), em que há uma incompatibilidade de seleção entre o sujeito da encaixada e seu verbo, e (26i), em que há violação de uma restrição quanto ao uso do singular nu, que não ocorre na posição de sujeito em sentenças existenciais: 
(26) a) O João falou que a menina saiu.

b) O Carlos viu que o leiteiro chegou tarde.

c) Ouvi dizer que o menino está doente.

d) O João viu o filme.

e) A Maria ouviu o boato sobre a saída do Pedro.

f) O Carlos disse que o quadro pintou.

g) O Carlos viu que o filme quebrou.

h) O Pedro leu que o sapato ficou caro.

i) A Márcia viu que sapato estragou.

j) A Márcia pensou que o filme cansou.

k) O João pensou que o sapato está apertado.

l) A Maria ouviu que a sonata terminou.

Por outro lado, se as sentenças com $\mathrm{SNu}$ forem aceitáveis, elas devem apresentar um padrão parecido com as sentenças consideradas "normais", como (26a) e (26d).

Como se pode notar, as sentenças, com exceção de (26d), têm a mesma estrutura: uma sentença matriz e uma sentença encaixada. É na sentença encaixada que ocorrem os dados que queremos verificar. Optamos por esse tipo de estrutura porque, num outro momento, iremos verificar o tempo de leitura de sentenças com SNu e com o definido genérico, com o intuito de testar a hipótese de Dobrobie-Sorin \& Pires de Oliveira (2007), de acordo com a qual há mais processamento sintático/semântico com o SNu. Como para o teste de tempo de leitura não é possível iniciar a sentença com o $\mathrm{SNu}$, dado que devemos manter o mesmo número de sílabas, optamos por colocá-los encabeçando sentenças encaixadas.

As 24 sentenças experimentais foram elaboradas tendo em vista as quatro estruturas que nos interessam comparar quanto à aceitabilidade, cada qual com 6 sentenças:

1. singular nu + predicado de espécie

2. definido singular + predicado de espécie.

3. singular nu + predicado episódico.

4. definido singular + predicado episódico.

Procuramos, sempre que possível, colocar as sentenças que aparecem em Müller (2000, 2002, 2003) como agramaticais - esse é o caso, por exemplo, das sentenças 2SEP, 9SESP abaixo -, com o intuito de verificar explicitamente o comportamento dos falantes com relação a esses dados. 
Para o nosso controle, as sentenças experimentais foram numeradas e classificadas segundo a tabela abaixo. EP significa "sentença episódica", enquanto ESP, "sentença de espécie". No primeiro bloco estão as sentenças com o artigo definido, daí a adjunção da sigla A; no segundo, as sentenças com o SN, por isso a presença da sigla S:

1AEP O João disse que o café chegou no Brasil em 1990.

2AEP A Maria ouviu dizer que a batata foi cultivada pela primeira vez na América.

3AEP O Pedro leu que o computador foi inventado por Babbage.

4AEP A Maria escutou que o carro entrou no Brasil no início do século.

5 AEP O João leu que o café foi introduzido no Brasil pelos europeus.

6AEP A Maria disse que o papel foi criado pelos chineses.

7AESP O Carlos disse que a batata é rara nessa região.

8AESP A Maria viu num programa que o rato se espalhou pela Europa.

9AESP O Carlos leu que a baleia está em extinção.

10AESP O João viu que o Mico Leão está extinto.

11AESP A Márcia leu que o tubarão está desaparecendo.

12AESP O João leu que o dinossauro foi extinto por um cometa.

1SEP O João disse que café chegou no Brasil em 1990.

2SEP A Maria ouviu dizer que batata foi cultivada pela primeira vez na América.

3SEP O Pedro leu que computador foi inventado por Babbage.

4SEP A Maria escutou que carro entrou no Brasil no início do século.

5SEP O João leu que café foi introduzido no Brasil pelos europeus.

6SEP A Maria disse que papel foi criado pelos chineses.

7SESP O Carlos disse que batata é rara nessa região.

8SESP A Maria viu num programa que rato se espalhou pela Europa.

9SESP O Carlos leu que baleia está em extinção.

10SESP O João viu que Mico Leão está extinto.

11SESP A Márcia leu que tubarão está desaparecendo.

12SESP O João leu que dinossauro foi extinto por um cometa.

As 24 sentenças experimentais foram agrupadas aleatoriamente em 4 grupos de 6 sentenças e foram, então, combinadas, aleatoriamente, com as 
12 sentenças distratoras; gerando 4 listas de 18 sentenças $^{9}$. As listas foram montadas de forma que numa mesma lista não ocorrem pares de sentenças em que a única diferença seja a presença ou ausência do artigo definido. $\mathrm{Na}$ frente de cada sentença dispusemos uma linha de $10 \mathrm{~cm}$ de comprimento iniciada por uma figura de um rosto sorridente $(;)$ e terminada por um rosto triste $:$. Conforme o esquema abaixo:

(27) O João leu que dinossauro foi extinto por um cometa. (-)

As instruções para o teste foram mínimas, a fim de evitar qualquer "contaminação". Aos informantes foi dada a ordem para que eles lessem as sentenças apenas uma vez e assinalassem imediatamente o grau de aceitabilidade da sentença. Eles deveriam indicar se a sentença parecia ou não familiar. Antes de aplicarmos o teste, foi realizado um teste piloto com 50 pessoas para verificarmos se as sentenças estavam adequadas. Essa aplicação piloto exigiu algumas alterações, em particular no tamanho das sentenças e nas palavras escolhidas, que foram, então, implementadas. O teste foi aplicado, na sua maioria, a alunos de nível universitário, de vários cursos, vindos de diferentes regiões do país, mas predominantemente de Santa Catarina.

Vale salientar que não existe relato de experiências anteriores que busquem testar a aceitabilidade de sentenças com o SNu. Logo, esse é um experimento original e deve, se possível, ser replicado.

Com o objetivo de fazer uma pesquisa quantitativamente relevante, aplicamos o teste em 200 informantes, sendo 50 para cada lista.

\section{Análise dos resultados}

Realizamos uma análise com base na medição proposta em Basso (2007).

De acordo com a proposta em Basso, dividimos a linha em três zonas: atribuímos nota 100 para os julgamentos que anotaram o rosto sorridente ou próximo dele; a nota 50 para os julgamentos intermediários, em que a anotação do falante apareceu entre o rosto sorridente e o triste; e finalmente, a nota zero para o rosto triste e sua proximidade:

9. Incluímos, no apêndice, uma das listas. 
(:). 100 50<smiles>[CaH]</smiles>

As sentenças gramaticais obtiveram um alto índice de aceitabilidade. Paralelamente, as sentenças que consideramos agramaticais receberam um baixo índice de aceitação, sugerindo, portanto, um paralelo entre gramaticalidade e aceitabilidade. $\mathrm{O}$ gráfico abaixo apresenta o resultado para a sentença distratora (26f), 'O Carlos disse que o quadro pintou', que consideramos agramatical ${ }^{10}$ :

\section{Tabela 1}

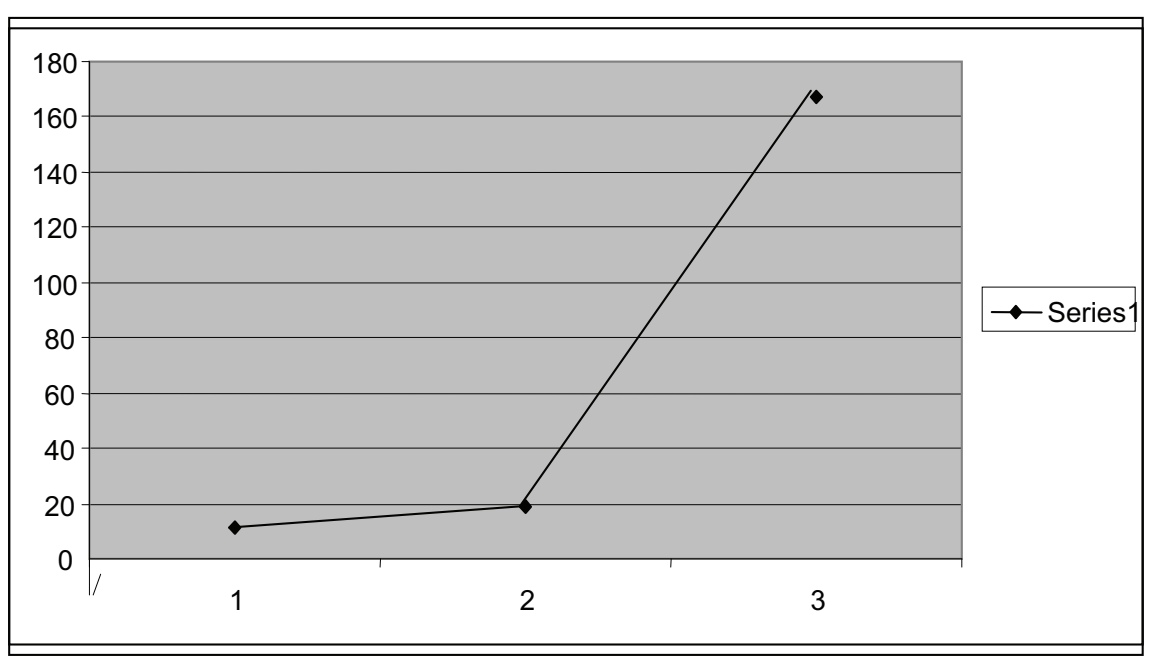

Em todas as tabelas a seguir, o índice 1 indica aceitabilidade plena, isto é, o falante assinalou a carinha risonha; o índice 2 indica os julgamentos intermediários; e o 3 indica a não aceitabilidade por parte dos falantes. As sentenças distratoras foram avaliadas por 200 falantes. Dos 200 sujeitos entrevistados, por volta de 10 consideram que essa sentença é normal. Uma possibilidade de explicação é que esses sujeitos estão atribuindo uma estrutura de "passiva" para essa sentença, algo como: o quadro foi pintado. Por volta de 20, julgam que ela é razoável, talvez pelo mesmo motivo. Mas a grande maioria considera, mais de 160 dos sujeitos avaliados, que essa sentença não é natural. Para eles, essa não é uma sentença familiar.

10. O resultado semelhante foi encontrado para as duas outras sentenças distratoras agramaticais, (26i) e (26j). 
Importante é notar o desenho do gráfico: uma curva ascendente vertiginosa na direção da não aceitabilidade, porque as sentenças agramaticais têm um alto grau de notas zero. As sentenças gramaticais mostram o padrão de curva inverso.

Nossa expectativa é de que se as sentenças com $\mathrm{SNu}$ são de fato agramaticais, elas devem apresentar um comportamento parecido com as sentenças como (26f) apresentado acima. No entanto, o contorno de aceitabilidade apresentado pelas sentenças com SNu não se assemelha ao contorno das sentenças agramaticais, como pode ser observado no gráfico a seguir, que mostra os resultados totais de aceitabilidade das sentenças que estamos investigando. Considerando-se todas as avaliações das 12 sentenças com artigo definido realizadas por 50 sujeitos, encontramos 389 sujeitos que consideram-nas boas, atribuindo-lhes a carinha soridente; 88 consideram que elas são mais ou menos e 123 avaliaram que essas sentenças não eram familiares, atribuindo-lhes a carinha tristonha. $\mathrm{O}$ número de indivíduos está, portanto, na vertical. Se compararmos esse resultado com o encontrado para as sentenças gramaticais, verificamos que o gráfico não é o mesmo. As sentenças gramaticais têm um gráfico acentuadamente decrescente: muitos as consideram plenamente aceitáveis e poucos regulares ou não aceitáveis. O gráfico para as sentenças com predicado de espécie é uma curva, como aparece representado abaixo:

Tabela 2

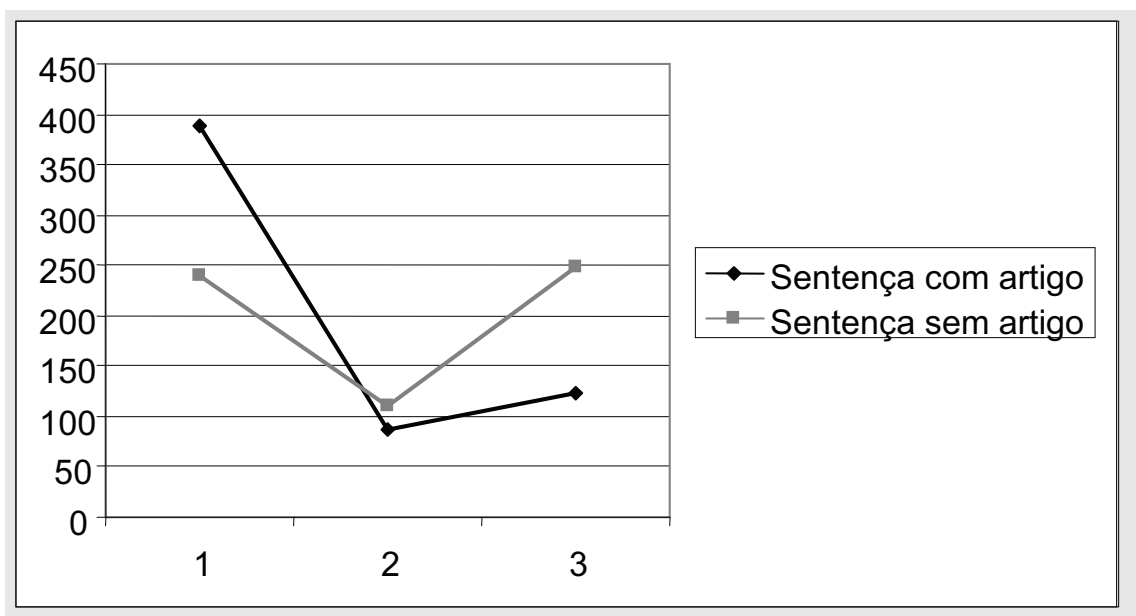


$\mathrm{Na}$ vertical está o número de sentenças avaliadas. Tomando-se as sentenças com SNu, das 600 avaliações, 259 sujeitos consideram-nas normais, assinalando a carinha sorridente; 111 avaliaram medianamente e 230 julgam que elas não são naturais.

Como se pode notar, a curva para as sentenças com predicado de espécie com e sem o artigo definido tem o mesmo padrão, embora as sentenças com o SNu tenham uma aceitabilidade menor. A questão que precisa ser mais bem entendida é porque as sentenças com o artigo definido não são plenamente aceitáveis. Uma resposta possível é que estamos num processo de mudança linguística em que as formas do definido genérico e do singular nu estão em competição. Assim, o gráfico acima parece sugerir que estamos num processo de variação em que convivem dois dialetos. Essa, no entanto, é uma hipótese que só podemos sugerir para outros estudos.

Em termos absolutos, as sentenças com $\mathrm{SNu}$ são plenamente aceitas para $43 \%$ dos falantes, enquanto que $38 \%$ entendem que elas não não naturais. As sentenças com o definido genérico são plenamente aceitas por $64 \%$ dos falantes, enquanto que $20 \%$ as tomam como não familiar.

Embora o resultado total não seja claro, é possível afirmar que ao menos para alguns falantes as sentenças com SNu podem se combinar com predicados de espécie. Logo, essas sentenças não são agramaticais.

Além desse resultado mais global, chamou-nos a atenção alguns resultados específicos que merecem uma discussão. Como já salientamos nem sempre sentenças com o artigo definido são aceitas pelos falantes. Houve dois casos em que a sentença sem o artigo definido foi considerada melhor do que a sentença com artigo. Um desses casos é a sentença 7AESP: 'O Carlos disse que a batata é rara nessa região' versus a sua contraparte sem artigo, 'O Carlos disse que batata é rara nessa região'. O predicado 'ser raro' é considerado um predicado de espécie pela literatura. Esperávamos, portanto, que a sentença com artigo definido fosse plenamente aceitável, ao passo que a com $\mathrm{SNu}$ fosse agramatical. No entanto, o resultado, apresentado na Tabela 3 abaixo, mostra que a sentença com o SNu é considerada melhor do que a sentença com o artigo definido. 
Tabela 3

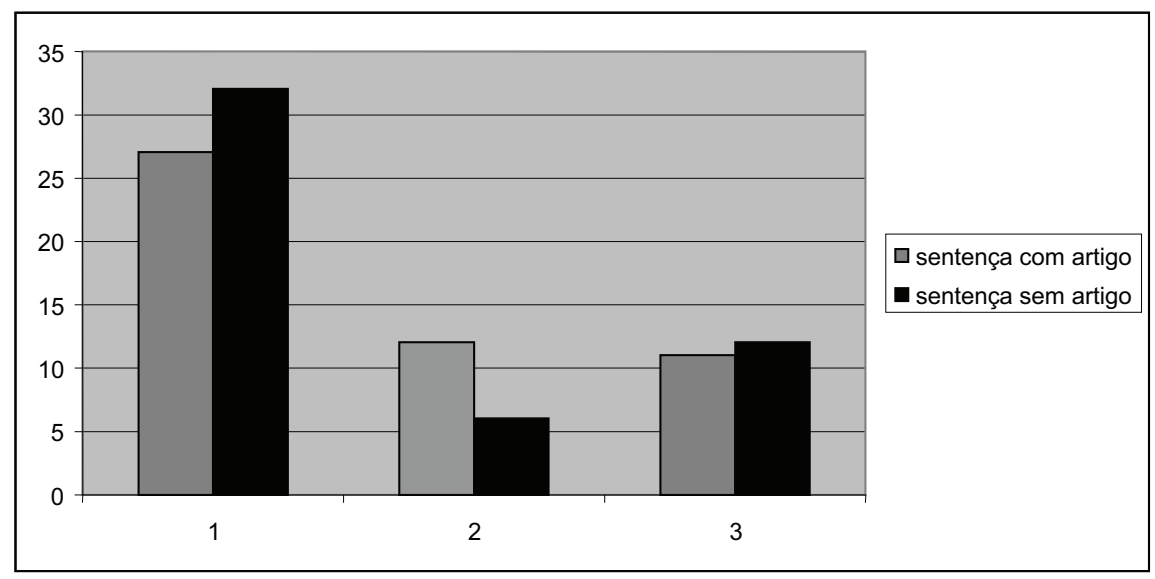

$\mathrm{Na}$ vertical estão os números de sentenças avaliadas, perfazendo um total de 50. Elas se distribuem conforme o grau de aceitabilidade. Em cinza estão os resultados das sentenças com artigo definido; em preto, as sentenças com SNu. Das 50 avaliações, mais de 30 com o $\mathrm{SNu}$ foram consideradas plenamente satisfatórias. Eles mostram que $64 \%$ dos falantes consideraram ótima a sentença com $\mathrm{SNu}$, contra $52 \%$ para a sentença com o definido genérico.

Uma explicação possível é que os falantes estão considerando 'batata' como um nome de massa, que são plenamente aceitáveis sem o artigo definido, por exemplo, 'Leite faz bem à saúde'. No entanto, ficam duas questões: 1. por que em outros exemplos em que o nome poderia ter sido considerado massivo isso não ocorreu? Esse é o caso da sentença 6AESP, 'A Maria disse que o papel foi criado pelos chineses' versus sua contraparte com SNu. O predicado 'ser criado' também é de espécie. Tampouco com predicados episódicos ocorreu dos falantes interpretarem o nome como massivo: 5 AEP, 'A Maria ouviu dizer que a batata foi cultivada pela primeira vez na América' versus a sua versão com $\mathrm{SNu}$, 'A Maria ouviu dizer que batata foi cultivada pela primeira vez na América'. Note que se trata do mesmo nome, 'batata'. 2. por que há pelo menos um outro caso em que a sentença com o SNu é ligeiramente preferencial? Trata-se do exemplo 10 SESP, 'O João viu que Mico Leão está extinto'. Não podemos considerar que 'Mico Leão' é um massivo. Não parece haver uma explicação clara para 
essa preferência dos falantes, a não ser, mais uma vez, que talvez estejamos diante de um processo de mudança linguística.

Com relação à distinção entre predicado de espécie e predicados episódicos, a análise mostrou que há uma clara preferência para o uso do definido genérico com sentenças episódicas, como pode ser visto comparando-se os gráficos abaixo. A Tabela 4 indica os resultados dos predicados episódicos e a Tabela 5 os resultados dos predicados de espécie.

Tabela 4

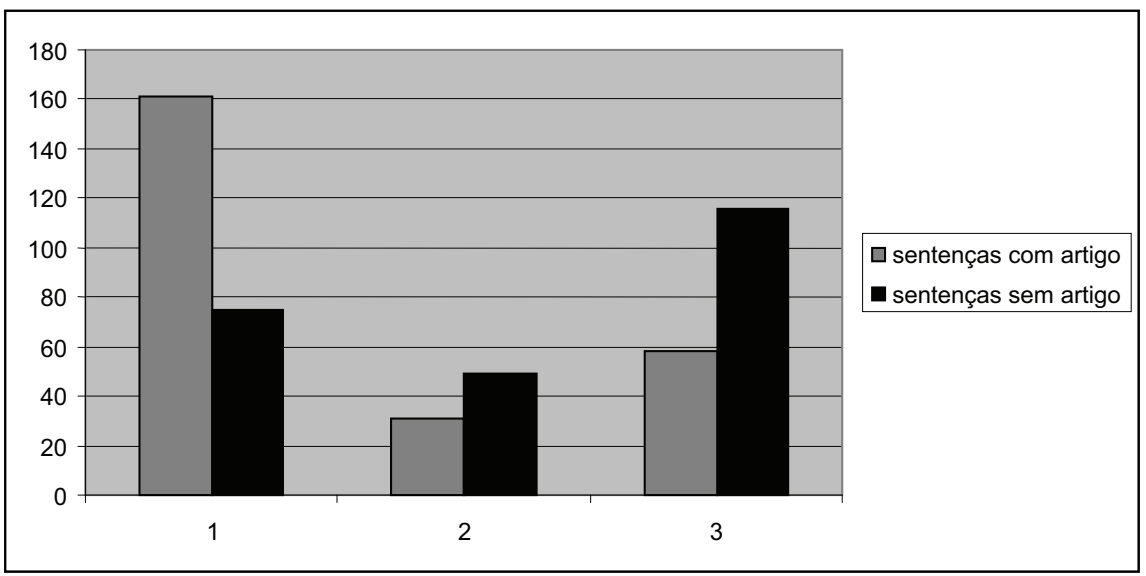

Tabela 5

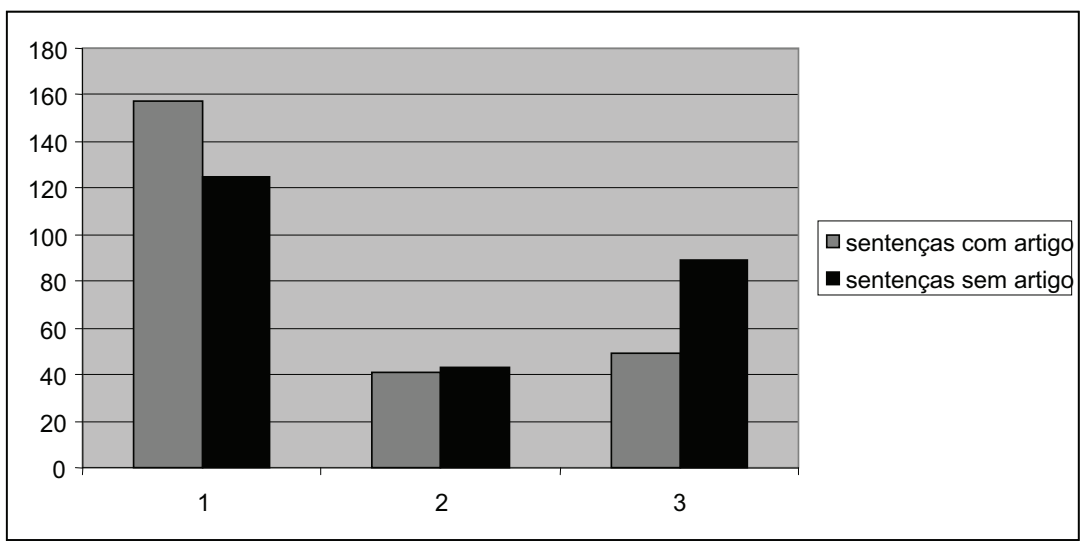


Mais uma vez, na vertical está o número de sentenças avaliadas relativamente ao julgamento. Na tabela em 4 podemos perceber que menos de 80 das 250 sentenças com SNu em sentenças episódicas foram avaliadas como plenamente satisfatórias, enquanto que 160 das 250 com definido genérico são aceitáveis para esses falantes. Com os predicados episódicos, o número de sentenças com SNu que são consideradas insatisfatórias supera o número dos que as consideram aceitável. É preciso uma explicação para esse fato. Uma sugestão é que os SNus não se combinam naturalmente com predicados episódicos, como é possível atestar pela sentença abaixo:

(28) \# Mulher discutiu futebol.

Como já apontado pela literatura (Schmitt \& Munn 2002, entre outros), sentenças como (28) só são aceitas quando em leitura de lista: na reunião ontem, mulher discutiu futebol, homem fez churrasco. Esse é um problema para o qual a literatura ainda não encontrou uma explicação.

\section{Conclusão}

Propusemos investigar se o singular nu no português brasileiro ocorre na posição de sujeito de sentenças com predicado de espécie e sentenças episódicas genéricas, com o intuito de esclarecer a controvérsia teórica entre Munn \& Schmitt (1999, 2005) e Pires de Oliveira et al. (2006), entre outros, versus Müller (2000, 2002, 2003). Como procuramos mostrar, essa controvérsia tem consequências teóricas importantes para a sintaxe e a semântica dos nominais nus em diferentes posições sintáticas. Nosso primeiro procedimento foi uma investigação em banco de dados de língua falada, nos corpus do Varsul e do Nurc, e em banco de dados escritos. Nos dados de bancos de língua falada, encontramos pouquíssimas ocorrências de predicados de espécie, num total de 23 sentenças. Dessas, apenas uma tinha um $\mathrm{SNu}$ como sujeito. Esse, no entanto, é um dado substancial, que confirma a hipótese de que o $\mathrm{SNu}$, ao menos para alguns falantes, pode ocorrer com predicados de espécie. Como dissemos, embora o conceito de gramaticalidade/agramaticalidade não seja esclarecido na literatura, parecenos que sentenças agramaticais não são produzidas espontaneamente; são antes artefatos do pesquisador para elicitar uma estrutura gramatical. Se esse é o caso, então esse único dado mostra que tratar a combinação $\mathrm{SNu}$ 
e predicado de espécie como agramatical é inadequado. Mas, além de ser apenas um único exemplo, notamos que o nome 'agricultura' poderia causar problema porque o conceito de espécie não é claro. Embora não tenhamos discutido em profundidade esse conceito, concluímos que dado o que a literatura nos oferece é possível tomá-lo como exemplo de espécie ou "kind" em inglês. Em banco de dados escritos, retirados da internet via Google, encontramos muitos casos de uso de $\mathrm{SNu}$ em títulos de artigos jornalísticos com interpretação de espécie (e não, como se poderia supor para leads de jornal, com interpretação específica), o que mais uma vez nos mostrou que ele pode se combinar com predicados de espécie. Encontramos também diversas ocorrências de $\mathrm{SNu}$ com predicado de espécie no corpo dos textos, indicando-nos que efetivamente essa combinação ocorre espontaneamento no PB. Finalmente, realizamos um teste psicolinguístico que verificou a aceitabilidade de sentenças com predicado de espécie e sentenças episódicas genéricas em que a posição de sujeito é ocupada ora pelo $\mathrm{SNu}$ ora pelo definido genérico. Embora os falantes prefiram sentenças com o definido genérico, não é correto afirmar que as sentenças com $\mathrm{SNu}$ são agramaticais, tendo em vista o comportamento das sentenças agramaticais, consideradas inaceitáveis pela grande maioria dos entrevistados. Os dados mostram que sentenças com $\mathrm{SNu}$ são aceitas ao menos por alguns falantes. O fato de que sentenças com definido genérico e sentenças com SNu mostraram o mesmo padrão nos sugere que estamos confrontados com um caso de variação, que merece ser mais bem estudado. Mostramos ainda que há casos em que as sentenças com SNu têm um índice de aceitação maior do que aquelas com o artigo definido, o que para nós reforçou a hipótese de variantes. Finalmente, parece haver uma ligeira interferência com relação ao tipo de predicado: embora o $\mathrm{SNu}$ se combine tanto com predicados de espécie quanto com predicados episódicos, ele é mais rejeitado com predicados episódicos. A explicação nesse caso parece estar no fato de que o $\mathrm{SNu}$ não se combina facilmente com predicados episódicos.

Assim, os dados empíricos atestam possibilidade do $\mathrm{SNu}$ se combinar com predicados de espécie, enquanto o teste de aceitabilidade parece indicar uma variação dialetal que merece ser estudada, já que os gráficos de aceitação do $\mathrm{SNu}$ e do definido genérico são isomórficos. Há, portanto, evidências de que o singular nu pode denotar espécie, a favor da posição teórica de Munn \& Schimtt (1999, 2005), Pires de Oliveira et al. (2006), entre outros. 
Enfatizamos que esse é um primeiro estudo empírico sobre a questão e que ele deve ser verificado por outros estudos.

Recebido em março de 2008 Aprovado em junho de 2009 E-mails: pires@cce.ufsc.br josa_coelho@hotmail.com. marianaufsc@yahoo.com.br

\section{REFERÊNCIAS BIBLIOGRÁFICAS}

BAsso, Renato Miguel. 2007. Telicidade e detelicização: semântica e pragmática do domínio tempo-aspectual. Dissertação de Mestrado. Campinas: Unicamp.

Chierchia, Gennaro. 1995. Individual level predicates as inherent generics. In: Carlson, G. N.; Pelletier, P. J. (Eds.). The Generic Book. Chicago: The University of Chicago Press, p. 176-223. . 1998. Reference to kinds across languages. Natural Language Semantics 6-4:339-405.

DAYAL, Veneeta. 2004. Number marking and (in)definiteness in kind terms. Linguistics and Philosophy 27: 393-405.

Dobrovie-Sorin, Carmen; Oliveira, Roberta Pires de. 2007a. Reference to kinds in Brazilian Portuguese: the definite singular vs. bare singulars. In: GrønN, Atle (Ed.). Proceedings of SuB12, Oslo: ILOS 2008, no prelo.

. 2007b. Bare Singulars in Brazilian Portuguese are Names of Kinds. Ms.

HeIm, Irene .1982. The Semantics of Definite and Indefinite Noun Phrases. Tese de Doutorado. Amherst: University of Massachussets.

Kratzer, Angelika.1995. Stage-Level and Individual-Level Predicates. In: Carlson, Gregory N.; Pelletier, Francis J. The Generic Book. Chicago: Chicago University Press, p. 125-175.

Krifka, Manfred; Pelletier, Francis J.; Carlson, Gregory N. et al. 1995. Genericity: and Introduction. In: Carlson, Gregory N.; Pelletier, Francis J. The Generic Book. Chicago: Chicago University Press, p. $1-124$. 
Link, Godehard .1983. The logical analysis of plurals and mass terms: a lattice-theoretic approach. In: BäUERLE, Rainer; SCHWARZE, Christoph; Stechow, Arnim von (Eds.).

Meaning, Use and the Interpretation of Language. Berlin: Walter de Gruyter, p. 303-323.

Müller, Ana Lúcia. 2000. Sentenças genericamente quantificadas e expressões de referência a espécies. Cadernos de Estudos Linguísticos 39. Campinas: Unicamp. . 2002. The Semantics of Generic Quantification in Brazilian Portuguese. PROBUS, 14:279-298.

.2003. A expressão da genericidade nas línguas naturais. In: MülLer, Ana Lúcia; Negrão, Esmeralda V.; Foltran, Maria José (Orgs.). Semântica formal. São Paulo: Contexto.

Munn, Allan; Schmitt, Cristina. 1999. Against the nominal mapping parameter: Bare nouns in Brazilian Portuguese. Proceedings of NELS 29. . 2005. Number and indefinites. Lingua 115:821-855.

Pires de Oliveira, Roberta; Santolin, Fabiana; Cruz, Ronald Taveira da. 2006. Bare singular: Evidence from Brazilian Portuguese. EVELIN. Ms.

SANTolın, Fabiana. 2006. O singular nu no português brasileiro. Dissertação de Mestrado. Florianópolis: UFSC.

Schmitt, Cristina; Munn, Allan. 2002. The syntax and semantics of bare arguments in Brazilian Portuguese. Linguistic Variation Yearbook 2:253269. 

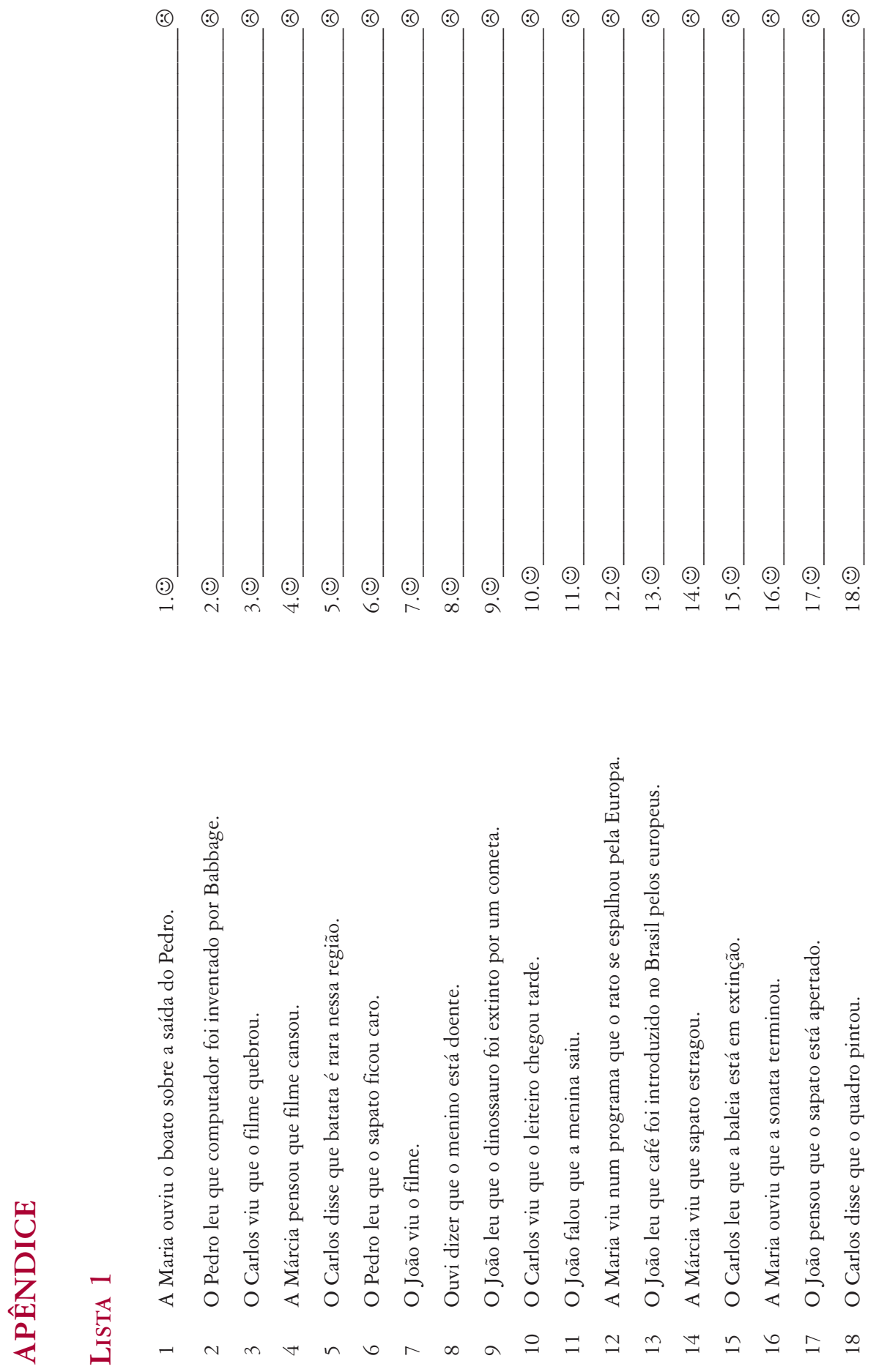